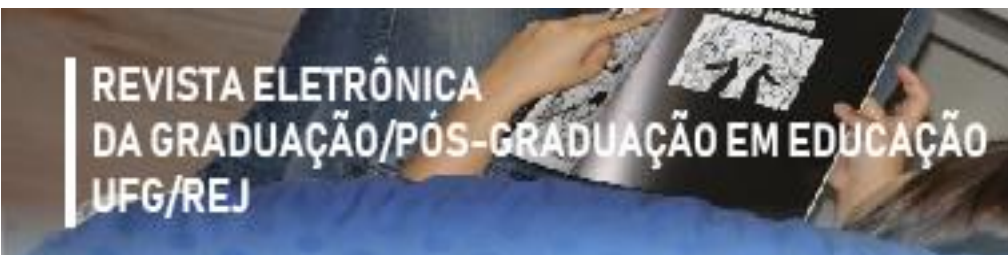

\title{
RAZÃO ALUNO/PROFESSOR E CARGA HORÁRIA EM ENSINO DE GRADUAÇÃO NA REGIONAL JATAÍ DA UFG - ANÁLISES PRELIMINARES
}

Sandra Aparecida Benite Ribeiro ${ }^{1}$ Ana Carolina Gondim Inocêncio ${ }^{2}$

RESUMO: No presente estudo, com o intuito de avaliar se o quantitativo de docentes é suficiente para a consolidação dos cursos de graduação da Universidade Federal de Goiás, Regional Jataí (UFG/REJ), foram analisadas as cargas horárias dos docentes no ensino de graduação, as cargas horárias dos Projetos Pedagógicos dos Cursos (PPCs), as divisões de turmas nas aulas práticas e a identificação dos cursos que ministram disciplinas em outros cursos, considerando-se o número de vagas autorizadas pelo Ministério da Educação (MEC). Ressaltamos que somente a carga horária de aulas na graduação foi considerada, de forma que os componentes curriculares ministrados nos cursos de pós-graduação, atividades administrativas e acadêmicas, de pesquisa e de extensão não foram computadas. Pela análise da carga horária dos PPCs, seriam necessários 502 docentes no total, para que houvesse esta consolidação, ou seja, seria necessária a contratação de mais 181 professores. Entretanto, pela avaliação da razão entre alunos e docentes, essa ficaria abaixo da razão preconizada pelo MEC. Neste sentido, sugerimos que inicialmente ocorra a adequação das cargas horárias dos PPCs ao mínimo exigido pelo MEC. Essa ação contribuirá para amenizar os problemas de cargas horárias excessivas de docentes nos cursos de graduação. Permitirá também que a metodologia adotada neste estudo, as análises e as conclusões sejam mais fidedignas. Além disso, consideramos imprescindível que as atividades em ensino na pós-graduação sejam também contabilizadas em estudos futuros.

Palavras chaves: Gestão Acadêmica. Graduação. Consolidação de cursos.

\section{STUDENT / TEACHER RATIO AND TEACHING LOAD ON UNDERGRADUATE EDUCATION IN REGIONAL JATAÍ OF UFG - PRELIMINARLY ANALYSES}

\begin{abstract}
In the present study, to evaluate if the number of professors is enough for undergraduate courses consolidation at the Universidade Federal de Goiás/Regional Jataí (UFG/REJ), the ratio between hours professors teach in undergraduate courses, Pedagogical Projects of Courses (PPCs) and the number of openings authorized by the Ministry of Education (MEC) were analyzed. We emphasize that only teaching hours in undergraduate courses were considered, so that disciplines taught in postgraduate courses, administrative activities, research and extension workloads were not computed. By analyzing the hourly workload of PPCs, it would take 502 professors to have them accomplished, therefore, hiring 181 more professors would be necessary. However, evaluating the actual ratio between students and professors, this would be below the ratio recommended by MEC. In this sense, a possible solution would be the adequacy of PPC credits to the minimum required by MEC, an action that would contribute to lessen workload problems in undergraduate courses and for professors. It will also allow the methodology adopted in this study, the analyses and conclusions to be more reliable. In addition, we consider it essential that graduate teaching activities also be accounted for in future studies.

\footnotetext{
${ }^{1}$ Pós-doutorado pela Universidade do Porto, FADEUP, Portugal, em Fisiologia. Doutorado e mestrado em Ciências Biológicas (Zoologia) pela Universidade Estadual Paulista Júlio de Mesquita Filho. Graduado em Ciências Habilitação em Biologia pela Universidade Estadual Paulista Júlio de Mesquita Filho. Professora da Regional Jataí UFG sandrabenite@gmail.com

${ }^{2}$ Doutorado em Engenharia Elétrica e Computação pela Faculdade de Engenharia Elétrica e Computação (FEEC) da Universidade Estadual de Campinas UNICAMP. Professora do curso de Bacharelado em Ciências da Computação na Universidade Federal de Goiás - Campus Jataí. anacarolina.inocencio@gmail.com
} 
| REVISTA ELETRÔNICA

DA GRADUAÇÃO/PÓS-GRADU AÇÃO EM EDUICACAÇÃO

UFG/REJ

Key words: Consolidation of courses. Undergraduate studies. Planning.

\section{INTRODUÇÃO}

A história da Regional Jataí começou em março de 1980, quando, o reitor da UFG, professor José Cruciano de Araújo, assinou a Resolução 145 que criou o Campus Avançado de Jataí (CAJ), por meio de uma parceria com a Prefeitura Municipal de Jataí, com a divisão de gastos e de responsabilidades. O primeiro vestibular foi realizado no ano seguinte e ofertou vagas para os cursos de Química (20 vagas), Física (30 vagas) e Matemática (40 vagas). Em 1996 foi implantado o curso de Ciências Biológicas e em 1998 foram implantados os cursos de Agronomia e de Medicina Veterinária no Campus do Centro de Ciências Agrárias e Biológicas, denominado atualmente de Cidade Universitária. Antes da implantação dos projetos de Expansão das Instituições Federais de Ensino Superior e do Reuni, em 2004, o CAJ tinha apenas cinco servidores técnico-administrativos e 43 docentes pertencentes ao quadro da UFG. O funcionamento do Campus dependia, essencialmente, das contratações realizadas pela Fundação Educacional de Jataí, com recursos oriundos de um convênio firmado entre a UFG, o Estado de Goiás e a prefeitura de Jataí. Em 2005, com a implantação dos projetos de Expansão e, posteriormente, do Reuni, diversas ações administrativas e acadêmicas puderam ser implementadas - o número de cursos, de docentes, discentes, servidores e a estrutura física do Campus cresceu consideravelmente (UFG, 2017)

Atualmente, o Campus é denominado de Regional Jataí da Universidade Federal de Goiás e possui dois Campi: Riachuelo, no Centro da cidade onde funcionam 4 cursos de graduação, 2 especializações, 2 mestrados e 1 doutorado, além de ambientes administrativos, como recursos humanos e gestão acadêmica. O Campus Cidade Universitária José Cruciano de Araújo, localizado na BR 364, abriga 21 cursos de graduação, 7 cursos de especialização e 3 mestrados.

Após a implantação dos 25 cursos, a REJ conta com 4510 vagas autorizadas pelo MEC para ingresso de estudantes nos cursos das seguintes áreas do saber: a) Agrárias - Agronomia, Engenharia Florestal, Medicina Veterinária e Zootecnia; b) Biológicas e Saúde - Biomedicina, Ciências Biológicas (Licenciatura e Bacharelado), Educação Física (Licenciatura e Bacharelado), 
REVISTA ELETRÔNICA

DA GRADUAÇÃO/PÓS-CRADUAÇÃO EM EDUUCAÇÃO

UFG/REJ

Enfermagem, Fisioterapia e Medicina; c) Exatas - Ciências da Computação, Física, Matemática e

Química; d) Humanas - Direito, Geografia, História, Letras Português, Letras Inglês, Pedagogia (Noturno e Matutino) e Psicologia. A REJ ainda possui seis cursos de Mestrado (Agronomia, Geografia, Matemática, Educação, Biociência Animal e Ciências Aplicadas à Saúde), um de Doutorado (Geografia) e três de especialização. Para este quantitativo de cursos de ensino de graduação e de pós-graduação, em novembro de 2015 a REJ possuía 294 docentes, 34 com regime de trabalho de $20 \mathrm{~h}$ e 260 em regime de 40h dedicação exclusiva.

Para avaliar se o quantitativo de docentes é suficiente para a consolidação dos cursos de graduação da REJ, no presente estudo foram analisadas as relações entre carga horária dos docentes no ensino de graduação, a carga horária dos Projetos Pedagógicos dos Cursos e o número de vagas autorizadas para cada curso pelo Ministério da Educação (MEC).

\section{MÉTODOS}

Por meio de consulta documental foram obtidos: a carga horária no ensino de graduação, o número de vagas autorizadas para cada curso pelo Ministério da Educação (MEC), as regras dos conselhos de classe; as características e as exigências para a realização de aulas práticas e de estágios; e a razão aluno/professor das Universidades Federais obtido nas Sinopses Estatísticas da Educação Superior - Graduação do ano de 2015 (INEP, 2018). O curso de medicina foi excluído das análises, pois no momento que este estudo foi realizado o curso ainda estava em fase de implantação.

As cargas horárias $(\mathrm{CH})$ de cada habilitação e de cada turno foram fornecidas pelos coordenadores de curso por meio da extração das cargas horárias das disciplinas dos PPCs e foi realizada a digitalização em uma planilha para ajuste das horas ministradas pelos docentes de cada curso e pelo número de semanas de aulas por ano, visto que o ingresso de estudantes é anual. A CH dos componentes curriculares ofertada por docentes de outros cursos, que não o do PPC avaliado, foi subtraída do curso que a recebe e somada a $\mathrm{CH}$ do curso que a ministra. Por exemplo, a $\mathrm{CH}$ do componente curricular de Cálculo do curso de Agronomia, ofertado por docentes do curso de Matemática, foi somado ao cômputo geral de $\mathrm{CH}$ dos docentes do curso de Matemática e subtraído do curso de Agronomia. Para o cálculo da $\mathrm{CH}$ total de um componente curricular com conteúdo prático, a $\mathrm{CH}$ prática foi multiplicada pelo número de turmas necessárias para acolher 20 alunos em cada uma, considerando-se o número de vagas autorizadas pelo MEC. 
Em alguns casos específicos, foi aceita a justificativa do(a) coordenador(a) de curso que o número de alunos em cada turma deveria ser menor do que vinte (por exemplo em aulas práticas realizadas em hospitais).

O número de docentes foi obtido a partir de consultas ao departamento de Recursos Humanos, RH, em novembro de 2015. Neste período, a REJ contava com 294 docentes, entre os quais 1 graduado, 17 especialistas, 74 mestres e 202 doutores. O curso de Medicina tem 60 vagas disponíveis para a implantação do curso determinado pelo MEC, porém somente 33 docentes tinham sido contratados até o momento da pesquisa. Por causa disso, este curso foi excluído das análises. A CH média do docente foi calculada a partir da divisão do total de horas do PPC do curso pelo número de docentes, após o ajuste do número de horas ministradas pelo cursos e pelo número de semanas. Para o cálculo da razão aluno/professor, o número de vagas autorizadas pelo MEC foi dividido pelo número total de docentes de cada curso.

\section{RESULTADOS E DISCUSSÃO}

Na Tabela 1 são apresentadas as relações entre o número de docentes e as cargas horárias dos PPCs dos cursos. Pode-se observar que, para que o corpo docente cumpra com a oferta de todos os componentes curriculares da REJ, a carga horária média dos docentes somente nos cursos de graduação deveria ser de 16h/semana, sendo que nos cursos que têm que abrir várias sub turmas para obedecer às normas dos hospitais ou locais de estágios, tais como a Enfermagem e Fisioterapia, a carga horária média chegava a valores superiores.

A partir da ponderação de que o docente despenda 10 horas por semana somente com ensino em sala de aula para graduação, para ofertar a carga horária total da REJ, seriam necessários 502 docentes no total, ou seja, seria necessária a contratação de mais 181 professores. O número de docentes necessário para cada curso (com dedicação de 10h/semana no ensino de graduação) é apresentado na quarta coluna e na última coluna é apresentado o número de vagas necessárias por curso (Tabela 1).

É importante ressaltar que somente a carga horária de aulas na graduação foi considerada, de forma que os componentes curriculares ministrados nos cursos de pós-graduação, atividades administrativas e acadêmicas, de pesquisa e de extensão não foram computadas. Além de a REJ ter seis cursos de pós-graduação stricto sensu, vários docentes atuam em cursos de pós-graduação na Regional Goiânia e em outras Universidades. 
Assim, a partir da apreciação de que o número de docentes lotados nos cursos da REJ é bem menor do que o número de docentes necessário, podemos deduzir que há um déficit significativo no número de professores necessário para o cumprimento das atividades em sala de aula de graduação, com exceção dos cursos de Engenharia Florestal, História e Matemática.

Por outro lado, pela avaliação da razão aluno/professor (RAP) da Regional Jataí (tabela 2), pode-se observar que a razão atual, com 295 docentes, é próxima a 15; entretanto quando fazemos a razão aluno/professor pelo número de Matrículas (conforme metodologia do INEP), teremos uma razão entre alunos matriculados/professores de 10,45. Caso o número de docentes aumente para o total calculado, 476 docentes, a razão na Regional Jataí cai para 9 alunos/professor. Apesar desta baixa razão aluno/professor com um possível aumento de docentes, os valores são similares aos das relações aluno matriculados/professores encontrado no Brasil, nas Universidades Federais (Tabela 3) (INEP, 2018) 
Tabela 1 - Análise do número de docentes necessários para consolidação dos cursos de graduação da Regional Jataí

\begin{tabular}{|c|c|c|c|c|}
\hline Curso & $\begin{array}{l}\text { CH do } \\
\text { PPCs* }\end{array}$ & $\begin{array}{l}\text { CH média/docente } \\
\text { atual }\end{array}$ & $\begin{array}{l}\text { Docentes necessários } \\
\text { 10h/sem }\end{array}$ & Número vagas necessárias \\
\hline Agronomia & 7376 & 14 & 23 & 8 \\
\hline Biomedicina & 5736 & 16 & 18 & 7 \\
\hline Ciências Biológicas & 14321 & 17 & 45 & 17 \\
\hline Ciência da Computação & 4640 & 13 & 15 & 4 \\
\hline Direito & 6414 & 12 & 20 & 6 \\
\hline Educação Física & 9344 & 14 & 29 & 13 \\
\hline Enfermagem & 12167 & 21 & 38 & 22 \\
\hline Engenharia Florestal & 2624 & 9 & 8 & 0 \\
\hline Física & 4762 & 14 & 15 & 5 \\
\hline Fisioterapia & 12213 & 42 & 38 & 29 \\
\hline Geografia & 6176 & 16 & 19 & 7 \\
\hline História & 2472 & 10 & 8 & 0 \\
\hline Letras - Inglês & 3216 & 20 & 10 & 6 \\
\hline Letras - Português & 7001 & 27 & 22 & 14 \\
\hline Matemática & 3880 & 8 & 12 & 0 \\
\hline Medicina Veterinária & 8868 & 15 & 28 & 11 \\
\hline Pedagogia & 11511 & 15 & 36 & 13 \\
\hline Psicologia & 7252 & 13 & 23 & 10 \\
\hline Química & 7016 & 14 & 22 & 6 \\
\hline \multirow[t]{2}{*}{ Zootecnia } & 4552 & 14 & 14 & 4 \\
\hline & $\begin{array}{l}\text { Total: } \\
141541\end{array}$ & Média: 16 & Total: 442 & Total: 181 \\
\hline
\end{tabular}

$\mathrm{CH}=$ carga horária. ${ }^{*}$ Carga horária total ministrada no próprio curso e a oferta de disciplinas para outros cursos. Fonte: os autores, 2018

Apesar da razão ter sido calculada por curso, para algumas coordenações de curso, este indicador não é eficiente. Conforme exposto anteriormente, os cursos que possuem limitações para a oferta de estágio, tais como aqueles que ofertam estágios em Unidades de Tratamento Intensivo, passam pela exigência dos locais de estágio que permitem a entrada de no máximo 
dois estudantes. Com isso, o número de docentes necessário para acompanhar estes estudantes no estágio deve ser aumentado. Outra limitação deste índice relaciona-se ao número efetivo de estudantes que os cursos que ofertam disciplinas para outros, pois aí a RAP fica destorcida para baixo, já que os discentes são somados apenas nos cursos de origem.

Tabela 2 - Razão aluno/professor (RAP) da Regional Jataí estratificada pelos cursos

\begin{tabular}{|c|c|c|c|}
\hline Curso & $\begin{array}{l}\text { Total vagas } \\
\text { autorizadas }\end{array}$ & $\begin{array}{l}\text { RAP com o número de docentes } \\
\text { atual }\end{array}$ & $\begin{array}{l}\text { RAP com o número total de } \\
\text { docentes }\end{array}$ \\
\hline Agronomia & 300 & 20 & 13 \\
\hline Biomedicina & 160 & 15 & 9 \\
\hline Ciências Biológicas & 280 & 10 & 6 \\
\hline $\begin{array}{l}\text { Ciência da } \\
\text { Computação }\end{array}$ & 200 & 18 & 14 \\
\hline Direito & 300 & 21 & 15 \\
\hline Educação Física & 160 & 10 & 5 \\
\hline Enfermagem & 120 & 8 & 3 \\
\hline Engenharia Florestal & 250 & 28 & 28 \\
\hline Física & 160 & 16 & 11 \\
\hline Fisioterapia & 200 & 22 & 5 \\
\hline Geografia & 280 & 23 & 15 \\
\hline História & 200 & 25 & 26 \\
\hline Letras - Inglês & 120 & 30 & 12 \\
\hline Letras - Português & 200 & 25 & 9 \\
\hline Matemática & 160 & 13 & 13 \\
\hline Medicina & 360 & 11 & 6 \\
\hline Medicina Veterinária & 300 & 18 & 11 \\
\hline Pedagogia & 320 & 14 & 9 \\
\hline Psicologia & 160 & 12 & 7 \\
\hline Química & 160 & 10 & 7 \\
\hline Zootecnia & 120 & 12 & 8 \\
\hline Total & 4510 & 15 & 9 \\
\hline
\end{tabular}


Tabela 3- Razão Matrículas/Função Docente em Exercício - Extraída da Sinopse Estatística do Ensino Superior (INEP, 2018)

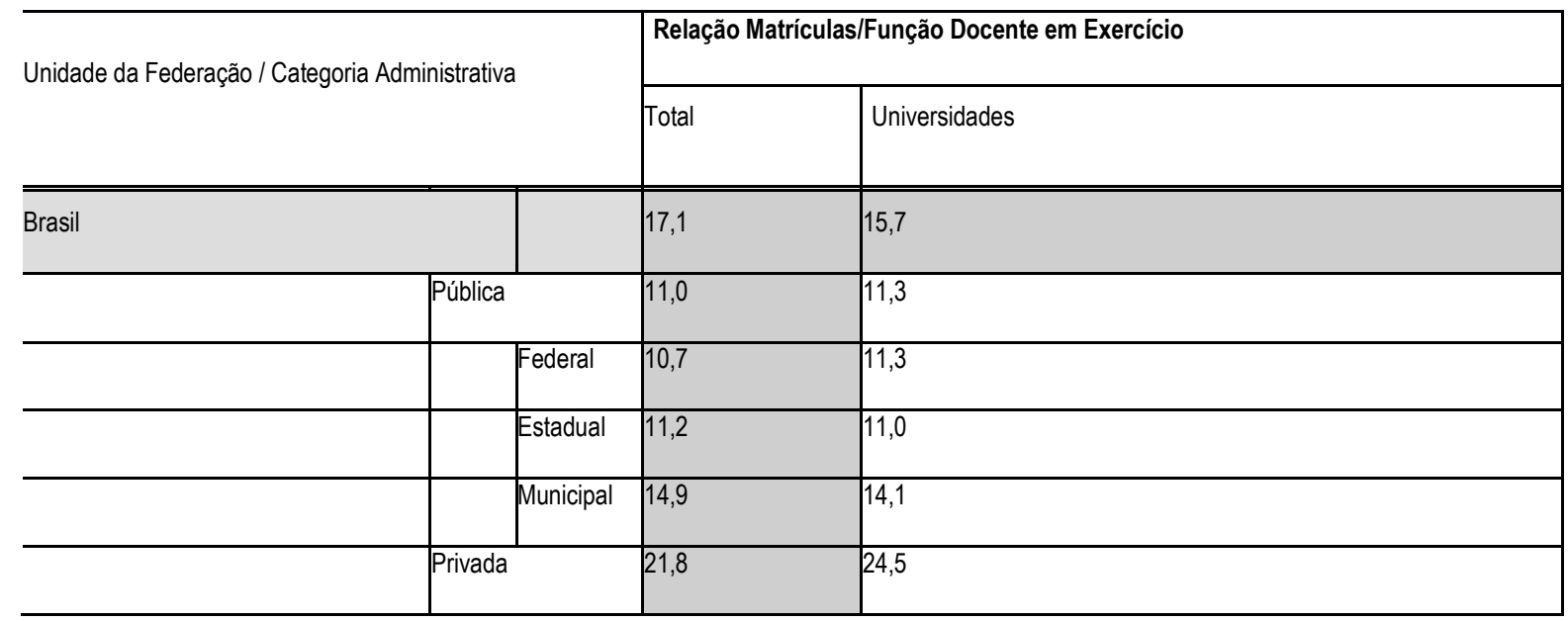

Fonte: Extraída do INEP, 2018 http://inep.gov.br/sinopses-estatisticas-da-educacao-superior

A soma geral de carga horária dos PPCs dos cursos da Regional Jataí supera, no total, em 10.946 horas aula a necessidade de horas preconizadas pelo MEC (Tabela 3), gerando um incremento na carga horária dos docentes em sala de aulas. A redução das cargas horárias dos PPCs é uma importante ação a ser executada para amenizar os problemas de cargas horárias excessivas nos cursos de graduação.

Tabela 3- Carga horária atual, prevista nas diretrizes do Ensino Superior e carga horária sobressalente de cada curso da Regional Jataí.

\begin{tabular}{llll}
\hline Curso & Carga horaria & \multicolumn{2}{l}{ Carga horária Carga horária } \\
& PPC & prevista & sobressalente \\
\hline Agronomia & 4320 & 3600 & 720 \\
\hline Biomedicina & 3528 & 3200 & 328 \\
\hline $\begin{array}{l}\text { Ciências Biológicas } \\
\text { (Bacharelado) }\end{array}$ & 3848 & 3200 & 648 \\
\hline $\begin{array}{l}\text { Ciências Biológicas } \\
\text { (Licenciatura) }\end{array}$ & 3760 & 2800 & 960 \\
\hline Ciências da Computação & 3232 & 3000 & 232 \\
\hline \begin{tabular}{l} 
Direito \\
\hline $\begin{array}{l}\text { Educação Física } \\
\text { (Bacharelado) }\end{array}$
\end{tabular} & 4440 & 3700 & 740 \\
\hline $\begin{array}{l}\text { Educação Física } \\
\text { (Licenciatura) }\end{array}$ & 3200 & 3200 & 0 \\
\hline \begin{tabular}{l} 
Enfermagem \\
\hline
\end{tabular} & 4446 & 2800 & 400 \\
\hline
\end{tabular}




\begin{tabular}{|c|c|c|c|}
\hline Engenharia Florestal & 4508 & 3600 & 908 \\
\hline$\overline{\text { Física }}$ & 2952 & 2800 & 152 \\
\hline Fisioterapia & 4180 & 4000 & 180 \\
\hline Geografia (Bacharelado) & 2856 & 2400 & 456 \\
\hline$\overline{\text { Geografia (Licenciatura) }}$ & 2974 & 2800 & 174 \\
\hline História & 2992 & 2800 & 192 \\
\hline $\begin{array}{l}\text { Letras (INGLÊS) } \\
\text { (ING) }\end{array}$ & 3048 & 2800 & 248 \\
\hline$\overline{\text { Letras (PORTUGUÊS) }}$ & 3048 & 2800 & 248 \\
\hline Matemática & 2800 & 2800 & 0 \\
\hline$\overline{\text { Medicina }}$ & 8000 & 7200 & 800 \\
\hline$\overline{\text { Medicina Veterinária }}$ & 4810 & 4000 & 810 \\
\hline Pedagogia & 3120 & 3200 & -80 \\
\hline$\overline{\text { Psicologia }}$ & 4584 & 4000 & 584 \\
\hline Quimica (Bacharelado) & 3288 & 2400 & 888 \\
\hline Química (Licenciatura) & 3208 & 2800 & 408 \\
\hline Zootecnia & 4104 & 3600 & 504 \\
\hline TOTAL & 94446 & 83500 & 10946 \\
\hline
\end{tabular}

Fonte: os autores

\section{CONSIDERAÇÕES FINAIS}

A partir do presente estudo concluímos que para os cálculos de docentes necessários para a consolidação dos cursos da Regional Jataí deve-se, inicialmente, adequar as cargas horárias dos PPCs, próximas ao mínimo exigido pelo MEC, para a realização de cálculos fidedignos e análises mais precisas. Além disso, consideramos que o cálculo da razão aluno/professor (RAP) não é eficiente, assim como cálculo de aluno/equivalente. Por exemplo, em cursos da área de saúde, nos quais é necessária a divisão dos estudantes em várias turmas para adequação às normas dos locais de estágio ou às regras do conselho de classe; ou em cursos que ministram disciplinas para outros e, nos quais, os discentes são somados apenas nos cursos de origem. Apesar das distorções metodológicas, consideramos necessária a contratação de docentes, haja vista que uma das metas da Universidade é a produção de conhecimento e isso só pode ser alcançado por meio do desenvolvimento de Pesquisas e da atuação dos docentes no ensino de Pós-graduação. Dessa forma, não é profícuo analisar se há ou não necessidade de contratação de docentes por meio da 
análise da RAP e sem considerar suas atividades na Pesquisa e na Extensão, ainda mais em um Campus que ainda está em processo de crescimento de consolidação.

\section{REFERÊNCIAS BIBLIOGRÁFICAS}

INEP. (2018). Sinopses Estatísticas da Educação Superior - Graduação. Brasília: Diponível em: http://inep.gov.br/sinopses-estatisticas-da-educacao-superior. Acessado em: 17 de maio de 2018.

UFG. (2017). Hitórico UFG Regional Jataí. Jataí: Disponível em: https://www.jatai.ufg.br/p/1889-historico. Acessado em 17 de maio de 2017. 